\title{
Inhaltsverzeichnis
}

\section{Age of Access?}

Grundfragen der Informationsgesellschaft

Vorwort zur Reihe - $\mathbf{V}$

Die Fragilität des Zugangs

Eine Kritik der Informationsgesellschaft — VII

1 Einleitung - 1

2 Eingang - 6

\section{Teil I: Platon}

3 Die Fragilität des Zugangs: Platonische Grundlagen - 11

$$
\begin{aligned}
& \text { Phaidros }-12 \\
& \text { Theaitetos }-16 \\
& \text { Symposion }-30
\end{aligned}
$$

4 Vertiefung: Hilfe und Muße als kognitive und ethische

$$
\begin{gathered}
\text { Grundbedingungen }-41 \\
\text { Hilfe }(\text { boètheia })-41 \\
\text { Muße }(\text { schole })-47
\end{gathered}
$$

\section{Teil II: Platons Leser/innen}

5 Die Schwierigkeit des Sich-Verstehens: Der innere Dialog zwischen Hans-Georg Gadamer und Jacques Derrida - 65

Gadamer und das Verstehen - 66

Derrida und das Missverstehen - 76

Widder -79

6 Die Ethik der Hilfe: Emmanuel Levinas' Platon-Lektüre - 95

Zwischenmenschliches Verstehen — 96

Sprache und Ansprache — 97 
Freiheit und ihre Grenzen - 103

Levinas' ethische boētheia 105

7 Denken als innerer Dialog: Innere Pluralität und vereinfachende Gewalt bei Hannah Arendt -121

The Life of the Mind: Die ethische Bedeutung des inneren

Dialogs - 121

Eichmanns Gedankenlosigkeit —-132

Die Verhinderung des Denkens im Totalitarismus — 136 Innere Pluralität — $\mathbf{1 4 1}$

Blumenbergs Unverständnis - 144

8 Adyton: Die Notwendigkeit des Innenraums bei Anne Dufourmantelle und Jacques Derrida — 153

Dufourmantelles Geheimnis -153

Derridas Gastfreundschaft 158

$9 \quad$ Humanismus und Berechenbarkeit: Der Dialog zwischen Ludwig Wittgenstein und Alan Turing als Ur-Ereignis der Informationsgesellschaft — 166

Missverstehen: Der erste Lösungsversuch - 166

Missverstehen: Der zweite Lösungsversuch — 168

Die Bedeutung eines Wortes — 172

Realistische Grammatik: Sprache als Vielfalt von

Handlungsinstrumenten - $\mathbf{1 7 8}$

Familienähnlichkeiten: Wittgenstein und Platon —183

Sprache als Interaktion — 197

Wittgensteins Mathematik_ 201

Wittgenstein und Turing -214

10 Der Angriff auf die Zukunft: Die Manipulation des kulturellen Gedächtnisses von Platon bis Jean-François Lyotard — 231

Der erste Angriff — 231

Arendts „gruesome quiet“_— 234

Orwells ewige Gegenwart — 237

Kunzrus Zukunft der Informationsgesellschaft — 244

Der reale Angriff — 250

Lyotard und die Logik des Schweigens - 255

Lesen lernen -267 


\section{Teil III: Gegenwart und Zukunft der Informationsgesellschaft}

11 Gegenwartspanorama: Die Schattenseiten der Informationsgesellschaft — 273

Boētheia und die Kritik des sofortigen Verstehens - 273

Information und die „Verdatung der Gesellschaft“— 282

Information und Dialog - $\mathbf{2 8 5}$

Information und Lesen $-\mathbf{2 8 7}$

Information und Übersetzen — 293

Die Automatisierung des Verstehens und die Hilfsbedürftigkeit der Sprache — 299

Scholē und die „Logik der Beschleunigung“ _-303

Scholē und die „Ökonomie der Aufmerksamkeit“ _-313

Scholē und die Bedrohung des Innenraums - 318

Der Respekt vor medialer Komplexität _- 324

Der Respekt vor der Komplexität des Menschen — 334

Der Respekt vor der Komplexität der Geschichte — 346

Contested heritage _ 349

Die kritische Funktion des Speichergedächtnisses _-355

Das kommunikative Kontinuum — 357

Fünf Kritiken, Scham und Mündigkeit - 362

12 Geistige Resilienz: Die gesellschaftliche Bedeutung von

Bibliotheken und Geisteswissenschaften - 371

Bibliotheken und Resilienz $\mathbf{3 7 2}$

Geisteswissenschaften und Resilienz — 390

Fragilität und Resilienz $-\mathbf{4 1 0}$

$13 \quad$ Einladung -417

$14 \quad$ Literatur $-\mathbf{4 2 0}$ 
